\title{
Experimental study and high-efficiency simulation of in-plane behavior of composite frame slab
}

\author{
Wen-Hao Pan ${ }^{1,2}$, Mu-Xuan Tao ${ }^{1, *}$, Chuan-Hao Zhao ${ }^{2}$, Ran Ding ${ }^{1}$, Li-Yan Xu ${ }^{1,3}$
}

1. Beijing Engineering Research Center of Steel and Concrete Composite Structures, Department of

Civil Engineering, Tsinghua University, Beijing 100084, China

2. College of Civil Engineering and Architecture, Zhejiang University, Hangzhou 310058, China

3. School of Transportation Science and Engineering, Beihang University, Beijing, 100191, China

Abstract: Experimental and numerical studies were conducted to investigate the in-plane behavior of the steel-concrete composite frame slab under cyclic loads. In the experimental study, an in-plane

11 loading test of a typical composite frame slab was designed by constraining its out-of-plane

12 deformations. The test observations, the load-displacement relationship, and the shear and flexural

13 deformation components were discussed to investigate the in-plane load resistant behavior and the

14 failure mechanism of the slab. The experimental results demonstrated an evident shear cracking concentration behavior and a pinching hysteretic curve associated with a typical shear-tension failure mode of the composite frame slab. In the numerical study, a high-efficiency modeling scheme based on the multiple vertical line element model (MVLEM) and the fiber beam-column element was developed for the test specimen. Comparisons with the experimental results showed that the developed model predicted the overall load-displacement relationship, the relationships associated with the shear and flexural deformation components, and the failure mode with a reasonable level of accuracy.

Keywords: Steel-concrete composite frame; Frame slab; In-plane; Shear; Experimental study; Fiber beam-column model. 


\section{Introduction}

26 The steel-concrete composite structures have been widely used in multistory and high-rise buildings.

27 For composite structures, the slab is one of the most complex structural components in a frame system.

28 Compared with the traditional RC slab, the composite frame slab has two main advantages: (1) the

29 composite action of the slab can increase the strength and stiffness of the beams, which further

30 enhances the strength and stiffness of the entire structure; and (2) the slab can prevent the top-flange

31 local buckling of the steel beams and improve the overall torsion resistant capacity. When a frame is

32 subjected to earthquake, the slab could work in two effects: the out-of-plane composite effect and the

33 in-plane effect.

The out-of-plane effect of the slab is due to the effective width of the slab that contributes to the

35 flexural behavior of the beams, as shown in Fig. 1. This out-of-plane composite effect plays a significant role in the lateral resistant performance of composite frame structural systems so that the lateral strength and stiffness of the frame can be improved. Many experimental researches have been carried out to investigate the out-of-plane composite effect in a composite frame system [1-5]. The out-of-plane composite effect is essentially a flexural-axial problem [6-8] of the beam and slab. This

flexural-axial problem has been studied by numerous researchers, including validated computational models such as the fiber beam-column model [8-12] and the multilayer shell model $[5,13,14]$. Tao el al. [6-8] conducted extensive numerical studies to investigate the effective slab widths associated with the ultimate loading capacity and the equivalent cross-sectional stiffness. A fiber beam-column model [8] considering this slab spatial composite effect for nonlinear analysis of composite frame systems has been proposed. Therefore, the out-of-plane effect of the composite slab has been well 


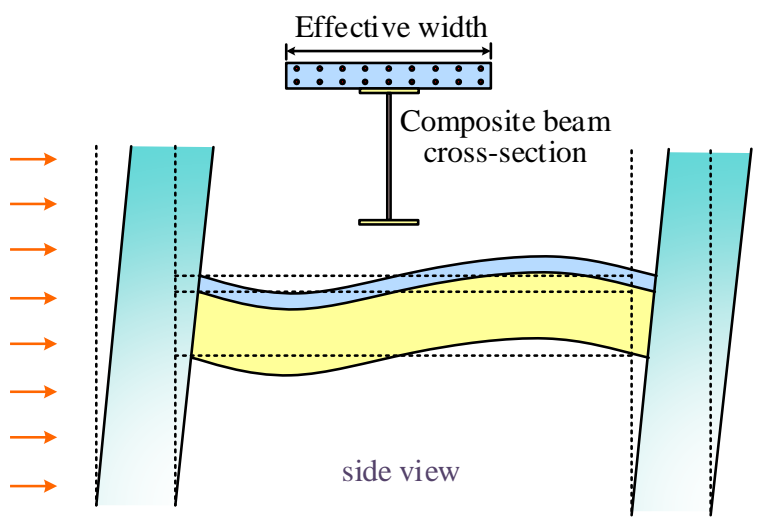

Fig. 1. Out-of-plane effect of the slab in a composite frame

The in-plane effect of the slab transmits the horizontal forces to the lateral load resisting systems through the deformation of the slab, as shown in Fig. 2. Due to the lack of experimental investigations

51 and appropriate computational models, the in-plane effect is usually handled by researchers in a

52 simple way. The assumption of an infinite in-plane stiffness of the slab, i.e., no in-plane deformation

53 of the slab, is often introduced in the current design practice. However, this simplification is only

54 suitable for simple regular structures. It may result in significant errors and even unsafe design results

55 in some structural systems [15-20], such as slabs with a large aspect ratio or with large openings.

56 Therefore, for a more rigorous design of composite frames, the in-plane effect of the slab requires

57 more investigations.

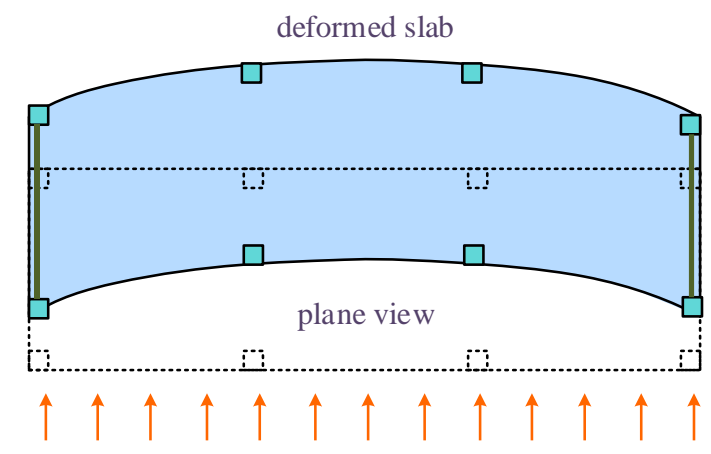

Fig. 2. In-plane effect of the slab 
61 experimental investigations on the in-plane effect of the slab were mainly focused on the concrete structural systems. From 1981, a research group in Lehigh University led by Huang and Lu [21-24] carried out a series of studies on the in-plane behavior of concrete slabs. The series of studies included experimental investigations on the stiffness, strength, and failure modes of beam-supported concrete slabs under in-plane loading [21,22]. The research group further worked with Panahshahi et al. [25] in the University at Buffalo on the seismic response of an RC frame with flexible floor diaphragms. For the steel-concrete composite frame slab, Sarkissian [26] conducted an experiment on the in-plane stiffness and strength behavior of a prefabricated composite frame slab. However, the experimental studies on the in-plane behavior of composite frame slabs under cyclic loading are still very limited to the authors' knowledge. the in-plane behavior of composite frame slabs. An effective computational model should be able to consider both the in-plane and out-of-plane effects of the slab. Such effective models may be classified into two categories, namely, refined models and high-efficiency models. The refined models for the slab [27-29] use shell or membrane elements to consider both the in-plane and out-ofplane effects of the slab. In general-purpose finite element programs (such as MSC.MARC, ABAQUS), this can be realized by using a multilayer shell element $[5,13,14]$. However, a refined model may be very time-consuming for the nonlinear seismic analysis of large structural systems. The high-efficiency models use beam elements with a composite cross-section to consider the outof-plane effect of the slab directly. In addition, the models may be more familiar to structural 
81 engineers in the design of composite structures, because the beam is usually designed based on the

82 internal force of the overall composite cross-section. However, the current high-efficiency models

83 [30-34] based on simple modeling schemes (springs, beam elements, and truss systems) could not

84 accurately simulate the in-plane deformations of the slab, especially when both the shear and flexural

85 deformations are not negligible. Therefore, a high-efficiency model for the composite frame slab

86 considering both shear and flexural in-plane deformations is required for the analysis and design of

87 composite structural systems.

88 To summarize, the in-plane behavior and the high-efficiency modeling scheme of composite

89 frame slabs are the essential problems for the analysis and design of composite structures. This paper

90 presents an experimental study and a high-efficiency modeling scheme of a composite frame slab

91 under in-plane cyclic loads. The crack development, the load-displacement relationship, and the shear

92 and flexural deformation components were discussed. The experimental results demonstrated an

93 evident shear cracking concentration behavior and a pinching hysteretic curve associated with a

94 typical shear-tension failure mode of the composite frame slab. A fiber-element-based MVLEM

95 modeling scheme for composite frames and frame slabs considering both the in-plane and out-of-

96 plane effects of the slab is then established. 


\subsection{Design of test set-up}

99 For a pure in-plane loading test of the slab, the test set-up was designed as Fig. 3. The in-plane loading 100 was applied via the in-plane MTS loading jack. The load and displacement were denoted as F and $\Delta$, 101 respectively. For the constraining of the out-of-plane slab deformations, two out-of-plane MTS 102 loading jacks were used. The displacements for the two out-of-plane locations were controlled to be 103 consistently zero, and the loads were applied by the MTS systems as $\mathrm{F}_{1}$ and $\mathrm{F}_{2}$.

104 height was $500 \mathrm{~mm}$. Considering the space size and capacity of the laboratory, a typical 1:2 reduced

111 scale was adopted. The length and width between steel beams of the specimen were $3500 \mathrm{~mm}$ and $1123000 \mathrm{~mm}$, respectively, and the thickness of the slab was $60 \mathrm{~mm}$.

\subsection{Design of specimen}

The specimen is a composite frame substructure including a slab, vertical beams, horizontal beams and two concrete filled steel tube (CFST) columns, as shown in Fig. 4. The specimen was designed based on a prototype of a typical $7 \mathrm{~m} \times 6 \mathrm{~m}$ composite slab with $120 \mathrm{~mm}$ thickness, and the steel beam
3000mm, respectively, and the thickness of the slab was 60mm.

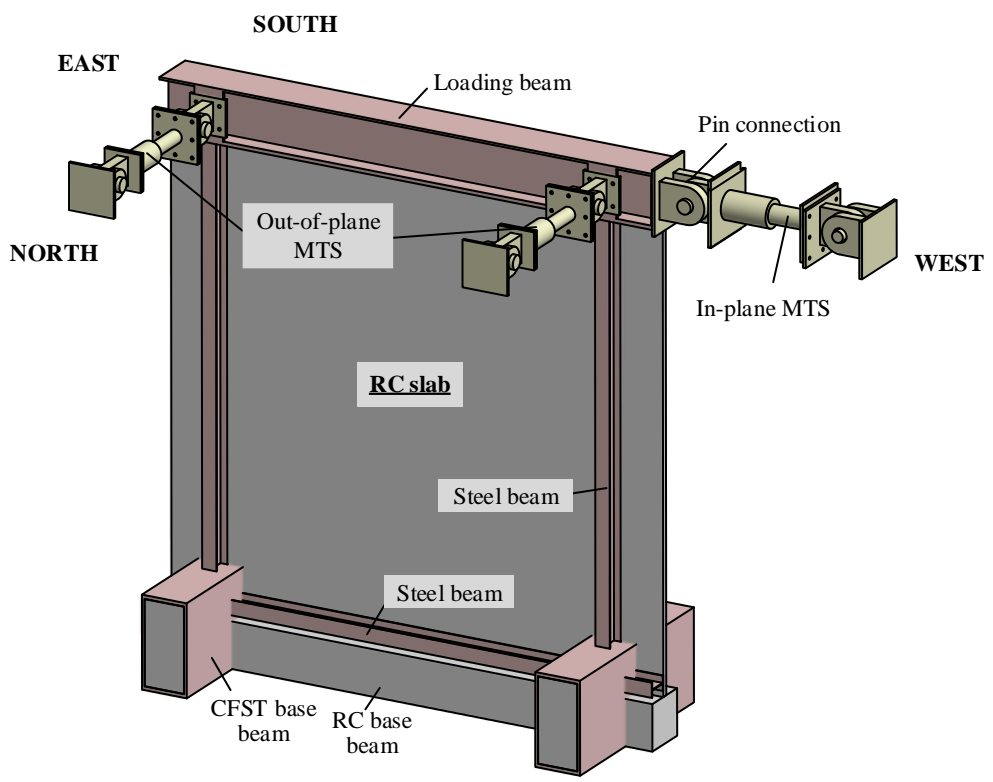

Fig. 3. Design of specimen and test set-up 


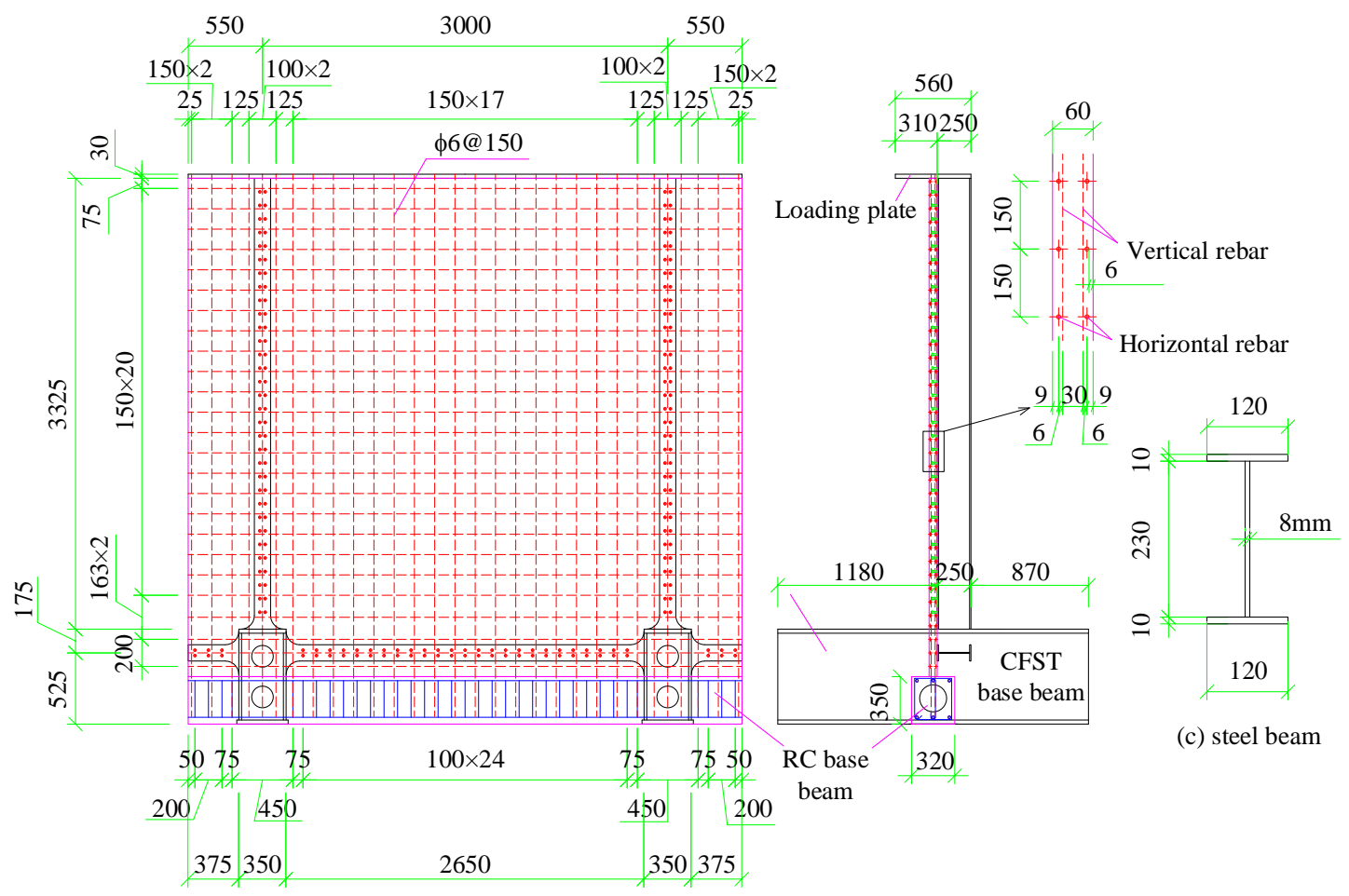
$3500 \mathrm{~mm}$ in height, and $(550+3000+550) \mathrm{mm}$ in width, where the $550 \mathrm{~mm}$ was the width on the outer provide a fixed boundary condition. The reinforcements (rebar) were arranged as two layers in both

Fig. 4. Detailed parameters of the specimen (unit: $\mathrm{mm}$ )

The details of the steel frame part are shown in Fig. 4(a). The specimen consisted of two $3325 \mathrm{~mm}$-long longitudinal steel beam, one 2650mm-long horizontal beam, and two CFST columns perpendicular to the slab for the anchored base. The cross-section of the steel beam is also shown in Fig. 4(c), having a depth of $250 \mathrm{~mm}$ and a flange width of $120 \mathrm{~mm}$. The thickness of the beam flange and web was $9.7 \mathrm{~mm}$ and $7.7 \mathrm{~mm}$, respectively. Shear studs were provided in two rows at a longitudinal spacing of $100 \mathrm{~mm}$. Their diameter and height were $13 \mathrm{~mm}$ and $45 \mathrm{~mm}$, respectively. Thus, a full shear connection capacity for the bending of the steel beam was ensured.

The details of the RC slab and the base beam are shown in Fig. 4(a and b). The RC slab was sides of the steel beams. The bottom end of the specimen was embedded in an RC base beam to longitudinal and horizontal directions, with a spacing of $150 \mathrm{~mm}$. And the thickness of concrete

(a) elevation view

(b) side view 
127 protective layer was $6 \mathrm{~mm}$. In addition, the base beam for the fixed boundary condition was designed

128 to be symmetric with respect to the RC slab, having a cross-section of $350 \mathrm{~mm} \times 320 \mathrm{~mm}$.

\subsection{Fabrication and material properties}

130 Fig. 5 shows the fabrication process of the specimen including the construction of the steel structure

131 [Fig. 5(a, b, and c)] and assembling of the slab reinforcement for casting concrete [Fig. 5(d)]. Fig.

$1325(\mathrm{e})$ shows the completion of specimen fabrication, and Fig. 5(f) shows the specimen under testing.

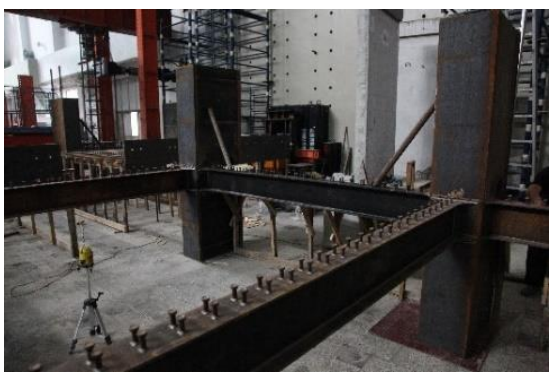

(a) Construction of steel structure

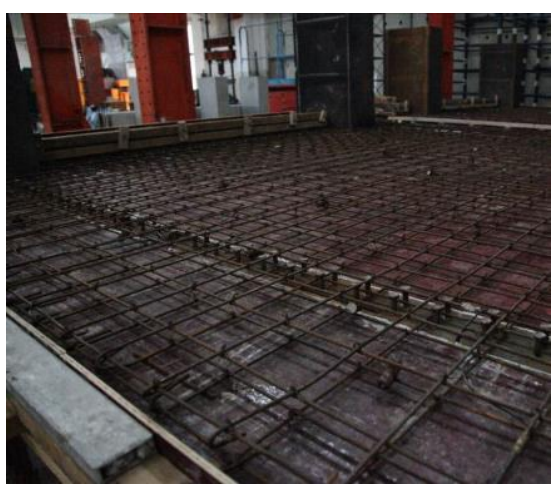

(d) Assembling slab reinforcement

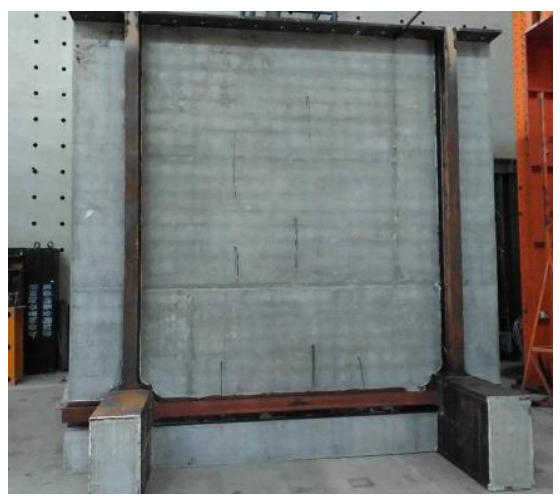

(e) Complete of construction

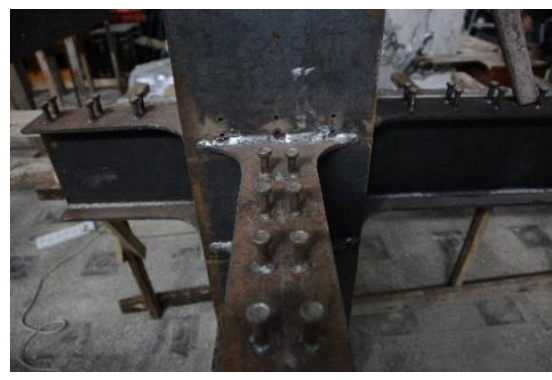

(b) Detail of steel beam

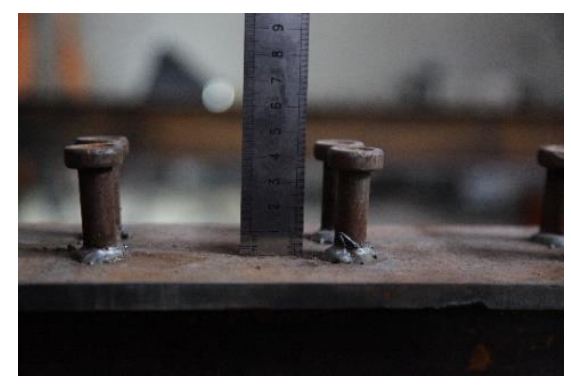

(c) Detail of shear stud

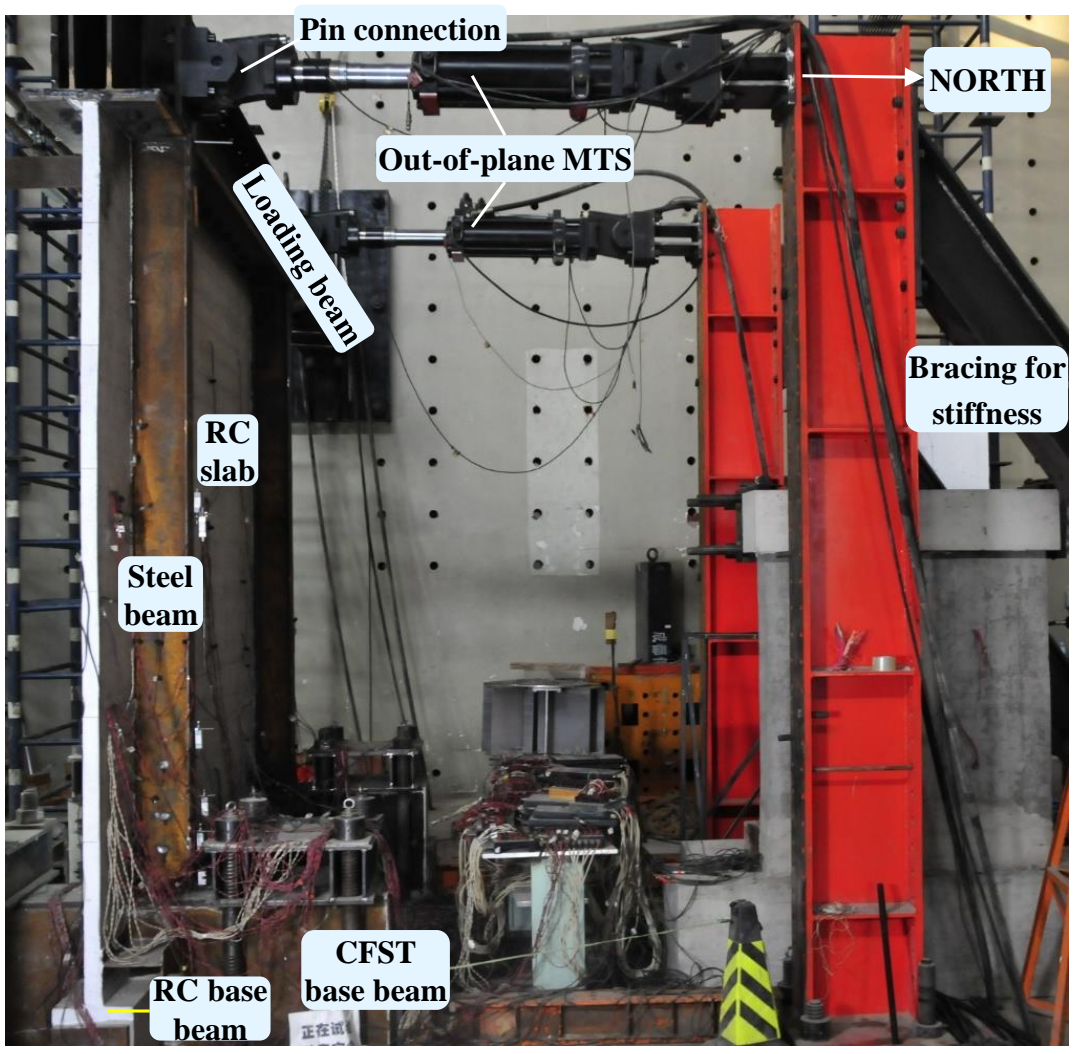

(f) Specimen under testing

Fig. 5. Fabrication of the specimen 
135 property tests are given in Table 1 . The 7.7-mm-thick steel plate and 9.7-mm-thick steel plate were 136 used in the web and flange of the steel beams, respectively. The two kinds of steel plates were tested 137 to have the same yield stress $f_{\mathrm{y}}$ and ultimate stress $f_{\mathrm{u}}$. In Table $1, k_{1}=\varepsilon_{\mathrm{sh}} / \varepsilon_{\mathrm{y}}$ and $k_{2}=\varepsilon_{\mathrm{u}} / \varepsilon_{\mathrm{y}}$ denote two 138 key factors for the shape of the stress-strain relationship curve, $\varepsilon_{\mathrm{y}}, \varepsilon_{\mathrm{sh}}$, and $\varepsilon_{\mathrm{u}}$ denote the strains 139 correspond to the initial yielding, the start of the strain hardening, and the ultimate stress, respectively. 140 For the concrete, the average cubic compressive strength (the side length of the standard cubic 141 specimens $=150 \mathrm{~mm}$ ) obtained on the same day of the model test was $54.2 \mathrm{~N} / \mathrm{mm}^{2}$, which corresponds 142 to a cylinder compressive strength of $43.4 \mathrm{~N} / \mathrm{mm}^{2}$.

Table 1 Material properties of steel plates and reinforcement (average values)

\begin{tabular}{ccccc}
\hline $\begin{array}{c}\text { Type of steel } \\
\text { or reinforcement }\end{array}$ & $f_{\mathrm{y}}(\mathrm{MPa})$ & $f_{\mathrm{u}}(\mathrm{MPa})$ & $k_{1}=\varepsilon_{\mathrm{sh}} / \varepsilon_{\mathrm{y}}$ & $k_{2}=\varepsilon_{\mathrm{u}} / \varepsilon_{\mathrm{y}}$ \\
\hline $\begin{array}{c}\text { 7.7-mm-thick } \\
\text { steel plate } \\
\begin{array}{c}\text { 9.7-mm-thick } \\
\text { steel plate }\end{array}\end{array}$ & 370 & 498 & 9 & 72 \\
$\phi 6$ reinforcement & 370 & 498 & 9 & 72 \\
\hline
\end{tabular}

\subsection{Loading procedure}

145 The loading procedure is shown in Fig. 6. The lateral load $F$ was applied using the force-control 146 scheme at each control point before yielding of the specimen and the displacement-control scheme 147 after yielding. In the force-control scheme, the cycle was applied once at each force control point, 148 and the controlled load level includes $\pm 200 \mathrm{kN}, \pm 400 \mathrm{kN}$ and $\pm 600 \mathrm{kN}$ (where + and - represent 149 positive and reverse loading, respectively, corresponding to the thrusting and pulling of the MTS 150 loading jack). In the displacement-control scheme, one displacement cycle was applied for each 151 displacement control point and then increased to the next loading level by $0.5 \Delta_{\mathrm{y}}$ relative to the 
152 previous cycle (where $\Delta_{\mathrm{y}}$ is the yielding displacement of the specimen determined in the experiment

153 based on the load-displacement curve and the strain measurements).

154

155

156

157

158
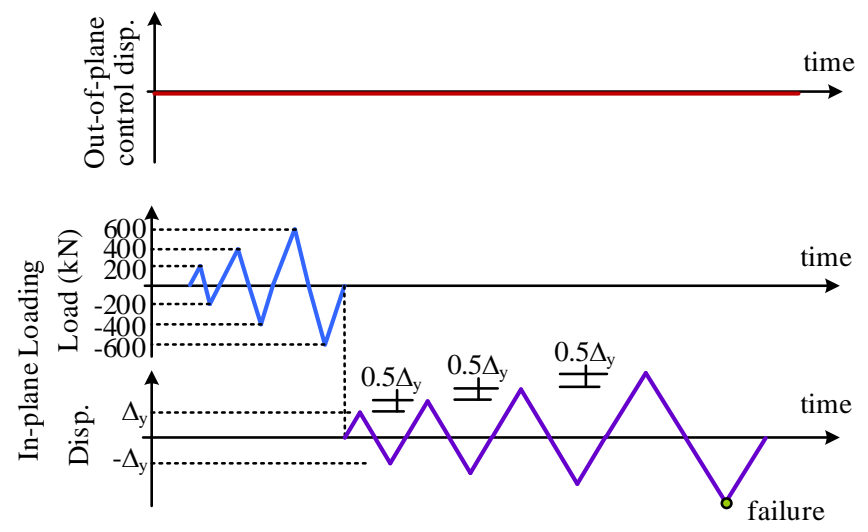

Fig. 6. Loading procedure

\subsection{Measurement arrangements}

Fig. 7 shows the arrangement of load and displacement measurements in the experiment. Built-in load cells were used for measuring the in-plane and out-of-plane loads.

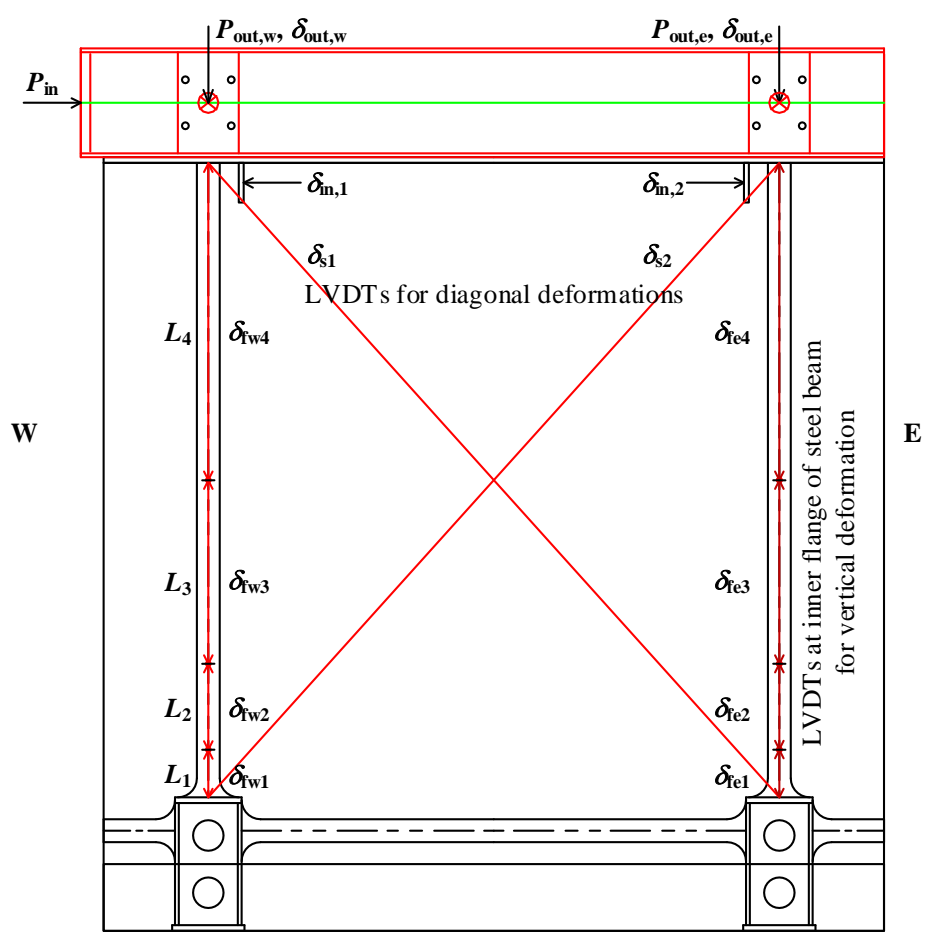

Fig. 7. Arrangement of main measurements

The measurements include:

(1) The load was measured by the force sensor of the three MTS jacks and directly output to the 
acquisition device, which is shown as $P_{\text {in }}, P_{\text {out, e }}, P_{\text {out, w }}$, respectively, where "in" and "out" represent

164 in-plane and out-plane, respectively, and "e" and "w" represent east side and west side, respectively.

(2) Displacement, as a macroscopic measurement, is more able to reflect the overall performance

166 of the test model, and has less dispersion than the measurement data that reflects local performance

167 such as strain. Therefore, the displacement measuring points were arranged in a plurality of important

168 parts in the test. The main displacement measured includes the displacement corresponding to the

169 load applied by the three MTS jacks: $\delta_{\text {in }}, \delta_{\text {out, e }}, \delta_{\text {out, w. In order to measure the in-plane shear }}$

170 deformation of the slab, the displacement gauges $\delta_{\mathrm{s} 1}$ and $\delta_{\mathrm{s} 2}$ were arranged to measure the

171 displacement difference of the diagonal end of the slab. In order to measure the in-plane flexural

172 deformation of the slab, two rows of displacement meters in series were arranged on the concrete at

173 the position of the steel beams to reflect the elongation and shortening of the steel beams. The two

174 rows of displacement meter numbers were respectively $\delta_{\mathrm{fe} 1}, \delta_{\mathrm{fe} 2}, \delta_{\mathrm{fe} 3}, \delta_{\mathrm{fe} 4}$, etc. and $\delta_{\mathrm{fw} 1}, \delta_{\mathrm{fw} 2}, \delta_{\mathrm{fw} 3}, \delta_{\mathrm{fw} 4}$,

175 etc. They can get the variation of the in-plane deformation curvature of the slab along the height of

176 the test piece.

177 (3) In addition, to analyze the strain distribution of the test model under load, especially the

178 deformation of key positions after cracking and yielding of the specimen, the test also placed many

179 strain measuring points on steel beams, steel bars and concrete. The strain measuring points on the

180 steel beam were concentrated at the inner and outer flanges of the beam bottom to measure the axial

181 strain of the steel beam in the longitudinal direction. The strain measuring points on the transverse

182 reinforcement were used to determine whether the test piece has shear yielding. The strain measuring

183 points on the concrete were arranged at the bottom of the slab to measure the axial strain of the 
concrete, which was used to determine whether the slab is cracked due to bending. A set of concrete strain gauges was also placed in the middle of the test piece to determine whether shear cracking occurred in the slab.

\section{Experimental results}

\subsection{Test observations}

The main test observations were the development of shear cracks [Fig. 8(a)] in the RC slab and the obvious stiffness degradations of the load-displacement relationship. Before the lateral load was increased to $400 \mathrm{kN}$, no evident experimental phenomenon was observed. The initial diagonal shear cracking of the slab occurred at the $+400 \mathrm{kN}$ loading level with a corresponding loading displacement of $3.5 \mathrm{~mm}$. Throughout the test, shear cracks developed with increases in the crack widths and the number of cracks, which resulted in a decrease in the crack spacing. In addition to the diagonal shear cracks, horizontal flexural cracks [Fig. 8(b)] also developed at the left and right sides of the RC slab. After the $\pm 600 \mathrm{kN}$ loading level, the load-displacement curve of the specimen showed a decrease in the stiffness, and many horizontal reinforcements in the slab yielded according to the strain measurements. Therefore, the lateral displacement of this loading level is defined as the yield displacement, and then the displacement-control scheme (Fig. 6) is followed. After the $\pm 1.5 \Delta_{\mathrm{y}}$ displacement-control level, few new cracks formed, whereas the main crack development was the increase in the crack widths of previously-formed cracks. The specimen exhibited a typical sheartension deformation mode, marked by two concentrated diagonal shear cracks in the middle of the slab and yielding of the horizontal and vertical reinforcements across these shear cracks. After the $4 \Delta_{\mathrm{y}}$ loading level, the load-displacement relationship showed large strength degradations. 
206 low compared to traditional RC members. Therefore, the composite frame slab showed a typical

207 shear-tension failure mode marked by two concentrated shear cracks that is common for RC shear

208 walls and coupling beam with relatively low reinforcement ratios [35,36]. Along with this typical

209 failure mode, the specimen had some secondary failure modes after the $4 \Delta_{y}$ loading level, including

210 slip between concrete and steel plate at the top of the specimen, longitudinal shear crack at the

211 connection between the slab and the steel beam [Fig. 8(c)], tension crack and compression crush of

212 footing concrete [Fig. 8(d)], and out-of-plane buckling of the slab [Fig. 8(e)]. The crack pattern on

213 the back of the specimen is shown in Fig. 8(f).

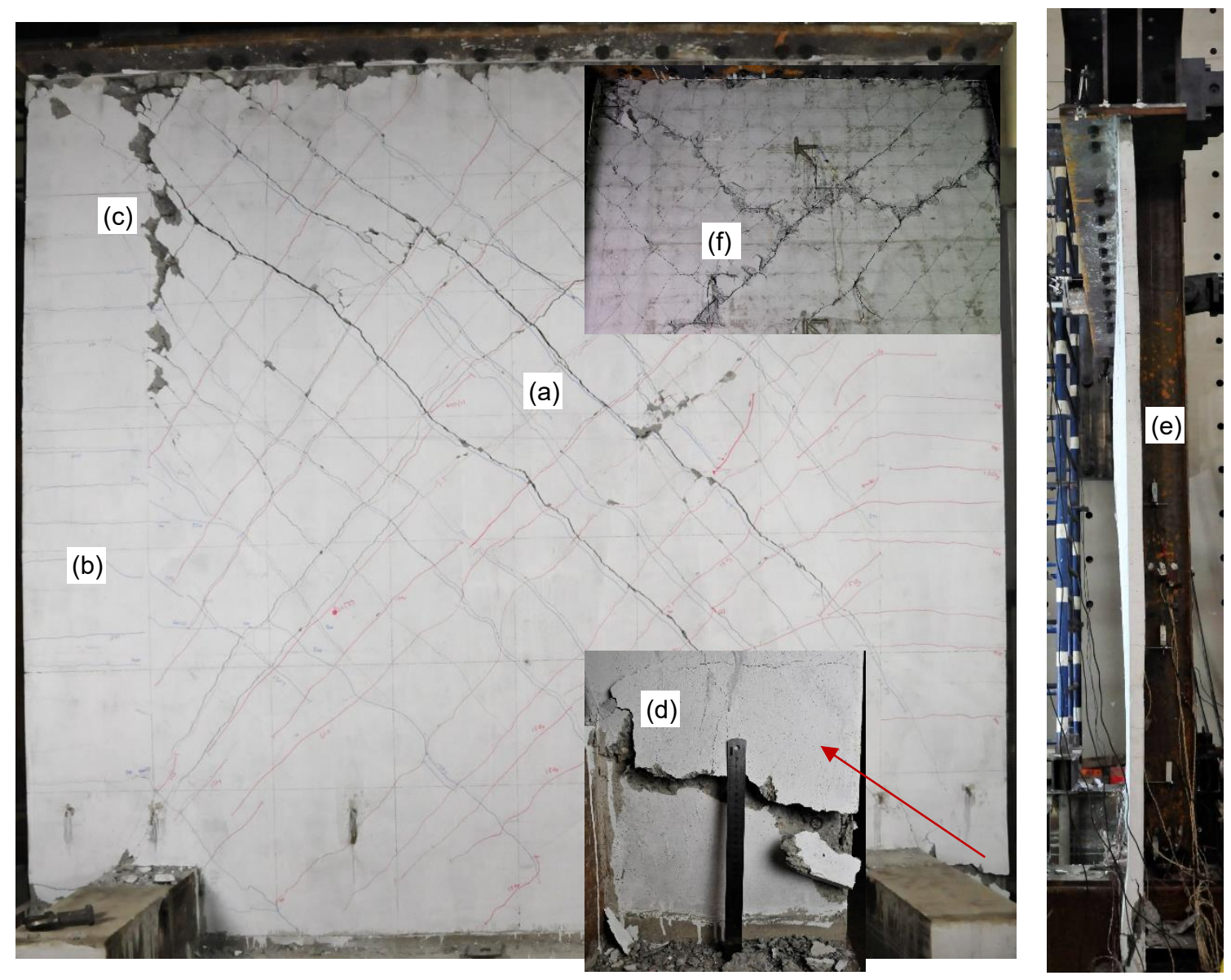

214 Fig. 8. Typical failure modes: (a) diagonal shear cracks; (b) horizontal flexural cracks; (c) cracks at the

215 connection between the slab and the steel beam; (d) tension cracking and compression crushing of footing 


\subsection{Load-displacement relationships}

218 The load-displacement curve is shown in Fig. 9. In general, the hysteretic curve of the specimen 219 corresponds to the load-displacement relationship of typical RC slabs with a shear-tension failure mode. After the ultimate load, the load-displacement relationship shows large stiffness and strength degradations. Due to the shear-tension failure mode, the hysteretic curve has an obvious pinching effect at the unloading and reverse loading stages. The ultimate load capacity of this specimen is $951.97 \mathrm{kN}$, and is $-927.09 \mathrm{kN}$ in the reverse loading direction.

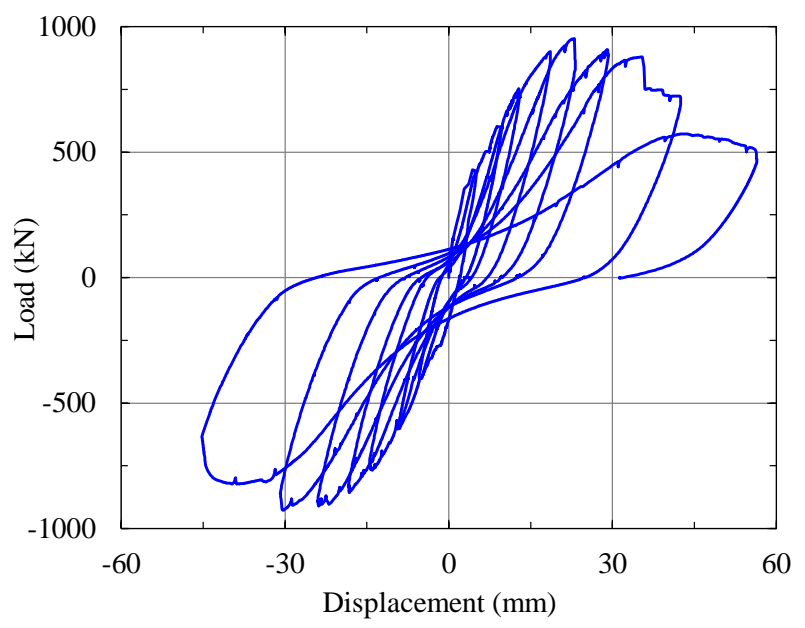

Fig. 9. Load-displacement hysteretic relationship

diagonal deformations $\delta_{\mathrm{s} 1}$ and $\delta_{\mathrm{s} 2}$.

$$
\Delta_{\mathrm{s}}=\frac{d_{\mathrm{s}}}{2 b}\left(\delta_{\mathrm{s} 2}-\delta_{\mathrm{s} 1}\right)
$$

where $d_{\mathrm{s}}$ is the diagonal length between the two vertical steel beams of the specimen; $b$ is the spacing of the two vertical steel beams. 
$231\left(\delta_{\mathrm{fe} 1}, \delta_{\mathrm{fw} 1}, \delta_{\mathrm{fe} 2}, \delta_{\mathrm{fw} 2}, \delta_{\mathrm{fe} 3}, \delta_{\mathrm{fw} 3}, \delta_{\mathrm{fe} 4}\right.$, and $\left.\delta_{\mathrm{fw} 4}\right)$ arranged at the east and west sides of the specimen. The 232 corresponding displacements at the east and west sides are used to calculate the total curvature of the 233 segment. The flexural deformation is calculated by using Eq. (2) based on the curvature area method.

$$
\Delta_{\mathrm{f}}=\sum \phi_{\mathrm{i}} d_{\mathrm{i}}=\sum \frac{\delta_{\mathrm{f} 2 \mathrm{i}}-\delta_{\mathrm{fli}}}{b} d_{\mathrm{i}}
$$

234 where $d_{i}$ is the horizontal distance between the center of the measured vertical slab segment and the

235 loading line; $\phi_{i}$ is the total rotation angle of each measured vertical slab segment.

Fig. 10 shows the hysteretic relationships between in-plane load and deformations. In addition to the total in-plane deformation, the shear and flexural deformations are also compared. It is noted that the deformations before the total displacement level of about $30 \mathrm{~mm}$ are compared due to the malfunction of one diagonal displacement gauge at later loading stages. It can be seen from the figure that the flexural deformation of the specimen is very small, whereas the shear deformation component accounts for more than $90 \%$ of the total deformation.

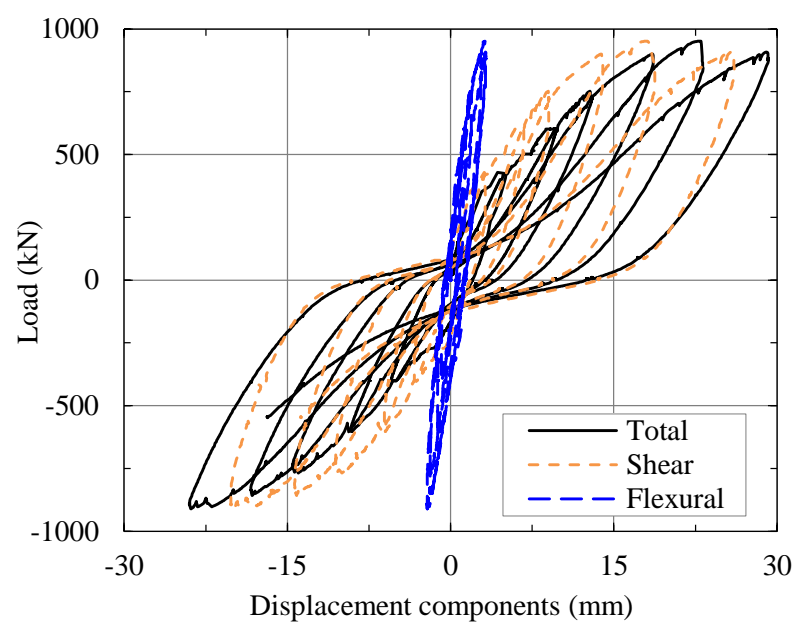

Fig. 10. Shear and flexural deformation components in the load-displacement hysteretic relationships 


\subsection{Model establishment}

246 The experiment exhibited a typical in-plane shear behavior of an RC slab. Therefore, if a multilayer

247 shell model $[5,13,14]$ is used, the key to accurately simulate such a shear-critical problem requires a

248 refined two- or three-dimensional concrete constitutive model. Such a constitutive model should 249 account for the inelastic shear response of reinforced concrete under cyclic loading, which can be 250 obtained from [37-42], among others. Since the refined two- or three-dimensional concrete 251 constitutive model for inelastic shear responses is not the focus here, this study utilizes the multiple 252 vertical line element model (MVLEM) [43-45] as shown in Fig. 11. Then, a high-efficiency modeling 253 scheme of the composite frame slab can be established.

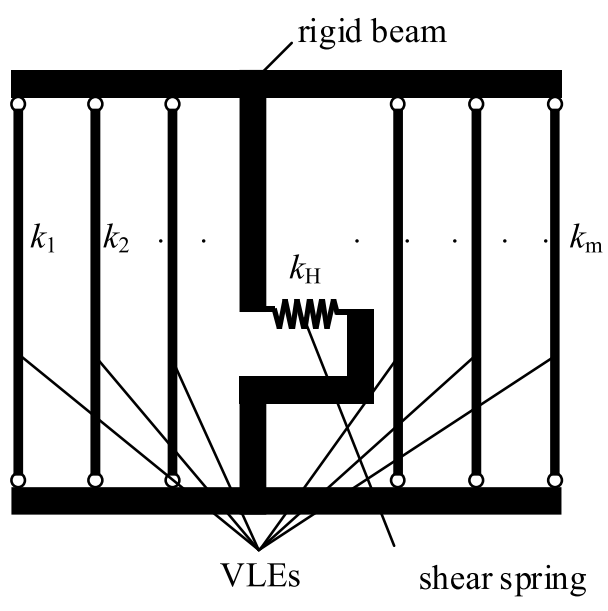

Fig. 11. Multiple vertical line element model (MVLEM)

The MVLEM is a high-efficiency model for considering both shear and flexural deformations of a shear wall. The MVLEM comprises rigid beams, some vertical line elements (VLEs), and a shear spring (Fig. 11). The model adopts the plane section assumption, therefore, the flexural deformation of the MVLEM is account for in the axial deformation of the vertical line elements, whereas the shear deformation is considered by the deformation in the shear spring. By specifying corresponding cross- 
261 sectional properties of the vertical line elements and the shear force-deformation constitutive 262 relationship of the shear spring, the MVLEM could accurately simulate the structural responses of a 263 shear wall.

264 In this study, the MVLEM for the in-plane shear experiment of the composite frame slab is 265 established based on a fiber-beam-model-based package on the general-purpose finite element 266 program MSC.MARC, namely, COMPONA-MARC [8,11]. This fiber-model-based program was 267 developed by our research team in 2014 and has been validated by comparing a large quantity of tests 268 of composite beams and frames.

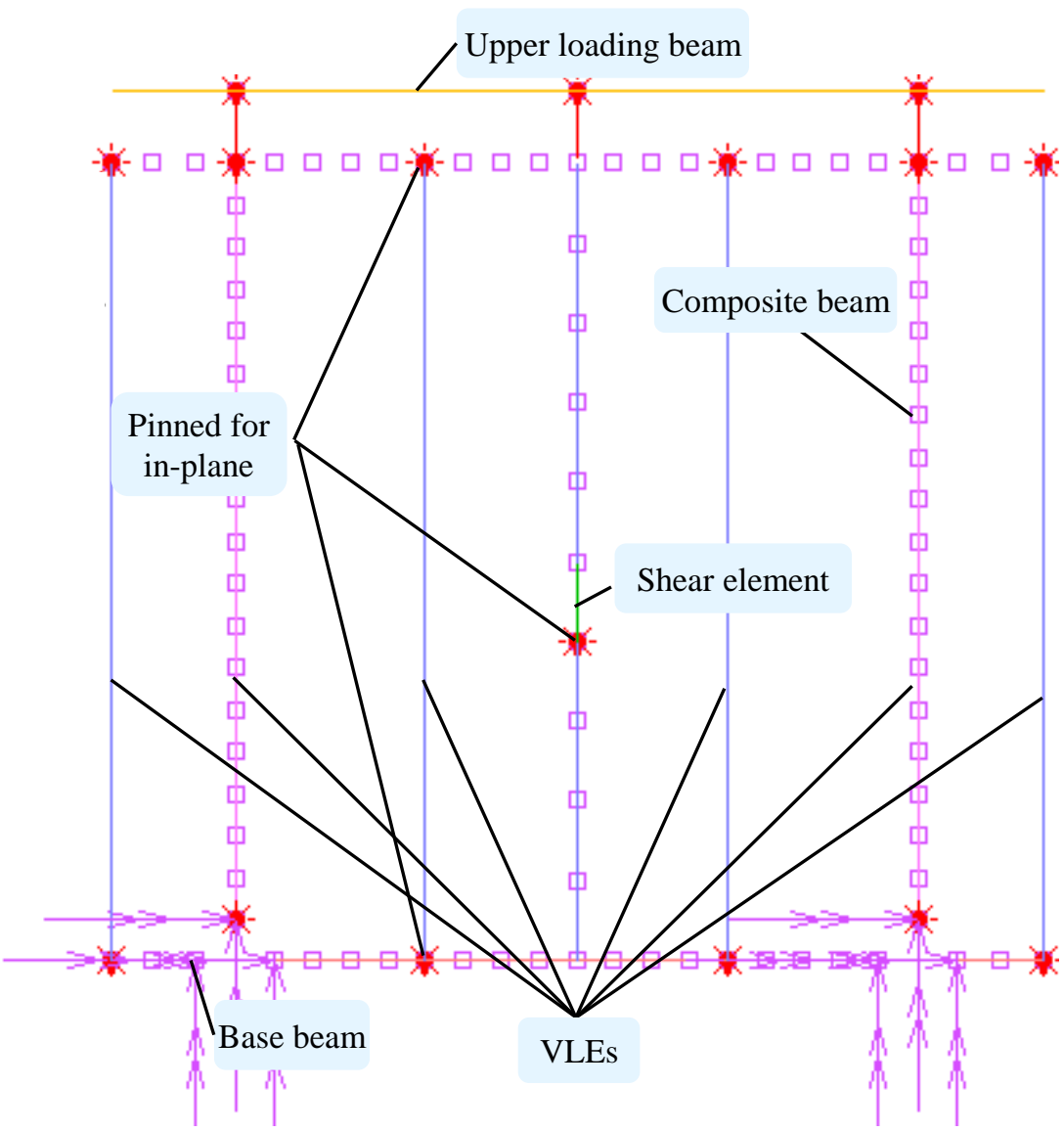

(a) front view

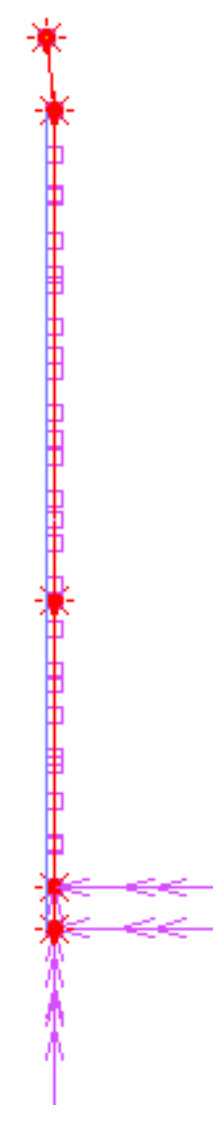

(b) side view

Fig. 12. Fiber-element-based MVLEM for simulation of the experiment

Fig. 12 shows the fiber-element-based MVLEM for simulation of the experiment. The in-plane 
271 connections between the vertical line elements and the upper/base beams are pinned connections. The

272 fiber sectional properties of the elements are determined based on their corresponding cross-sections

273 of the slab or beam. The shear spring in the MVLEM is realized here by using a shear deformation-

274 based fiber beam-column element $[35,36]$ in COMPONA-MARC.

275 Therefore, this MVLEM based on COMPONA-MARC can simulate both the in-plane flexural

276 and shear responses of the composite frame slab.

\section{$277 \quad 4.2$ Constitutive relationships}

278 The fiber beam-column element developed by Tao et al. $[8,11]$ for the nonlinear analysis of typical

279 RC and composite structural members was applied in this simulation. This element was developed

280 from a standard displacement-based beam-column element and was implemented in the general

281 commercial FE software MSC.MARC. The element mesh and section discretization for the fiber

282 beam-column elements of composite structural members are described in Tao et al. [11]. The uniaxial

283 stress-strain skeleton curve and hysteretic laws of the concrete, rebar, and steel for the fiber beam-

284 column model have also been validated [8-12] by comparing with a number of experiments.

285 The shear force-deformation constitutive relationship for the shear responses has been

286 established by Ding et al. [35,36] for shear-critical structural members. This constitutive relationship

287 for shear utilizes a trilinear skeleton curve which defines a shear cracking point and a shear critical

288 point. The hysteretic laws are defined to consider the obvious unloading stiffness degradation,

289 strength degradation and the pinching effect of typical shear-critical structural member under

290 cyclic loading. This shear force-deformation constitutive relationship has been implemented in a

291 shear deformation-based fiber beam-column element in COMPONA-MARC. The developed fiber 
model has also been validated in a number of shear-critical structural members $[35,36]$.

\subsection{Comparisons with experimental results}

294 Fig. 13 shows the experiment and simulation results of the deformation mode at the displacement

295 level $4 \Delta_{\mathrm{y}}$. The specimen exhibited a typical shear-tension deformation mode, marked by two 296 concentrated diagonal shear cracks in the middle of the slab and yielding of the horizontal and vertical 297 reinforcements across these shear cracks. The shear deformation mode of the specimen is reflected in 298 the deformation of the shear element in the MVLEM. As can be seen from the figure, the shear 299 elements in the model deform significantly at the diagonal of the middle of the slab, which is in good 300 agreement with the shear failure mode in the experiment. Therefore, the model can well simulate the 301 shear failure mode of the composite frame slab.

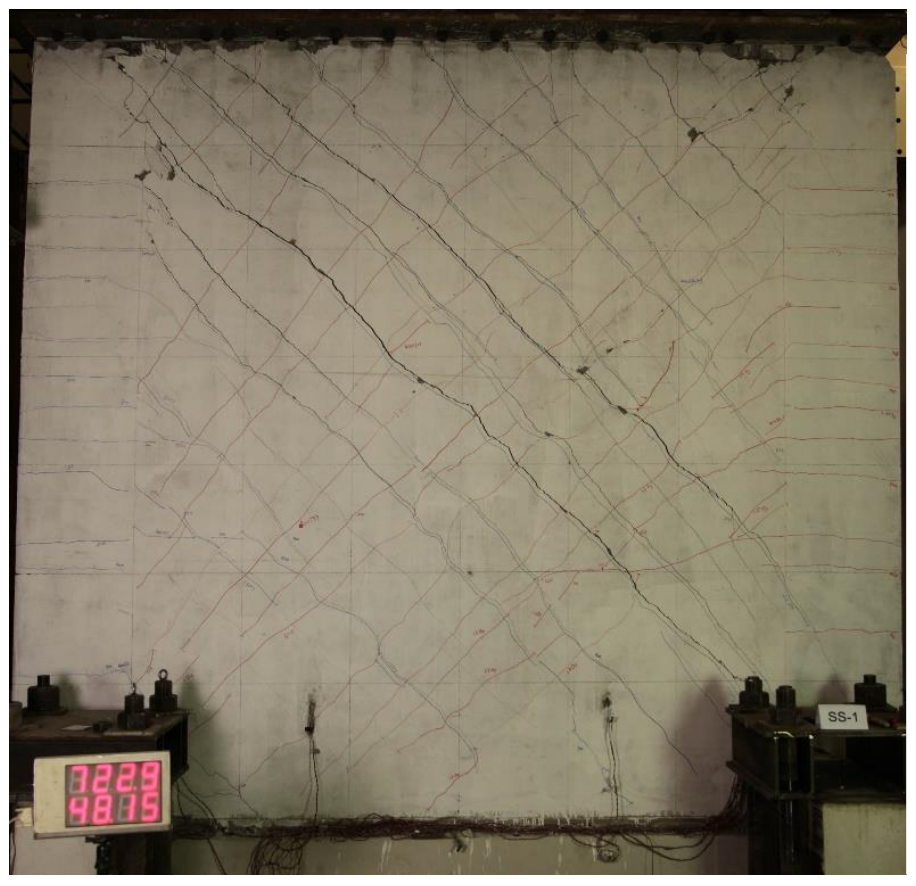

(a) experiment

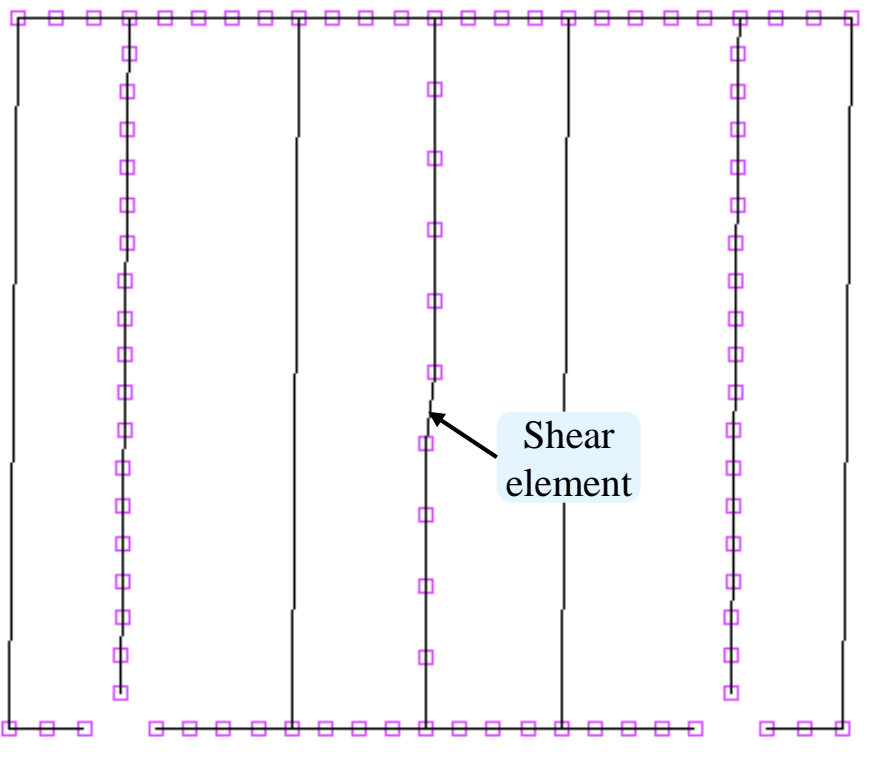

(b) FEA

Fig. 13. Comparison between experimental and FE results: deformation mode at displacement level $4 \Delta_{\mathrm{y}}$

Fig. 14 compares the measured load-displacement relationships with the numerical results 
Fig. 14(a). The comparison between the experimental and numerical results indicates that the developed MVLEM simulates the load-displacement relationships well. The numerical results slightly overestimated the initial stiffness and the lateral load capacity. However, the unloading stiffness and strength degradations as well as the pinching effect of the hysteretic behavior in the shear response were well captured by the developed model. In general, the developed model was able to predict the overall behavior of the composite frame slab with a reasonable level of accuracy.

313 14(c), respectively. The two figures show that the model can not only reflect the overall load-

314 displacement relationship, but also accurately predict the development of shear and flexural deformation components. This indicates that the MVLEM based on the traditional fiber beam-column model for the vertical line elements can accurately capture the flexural deformation of the slab. The shear deformation-based fiber beam-column element can also well simulate the shear deformation of the slab.

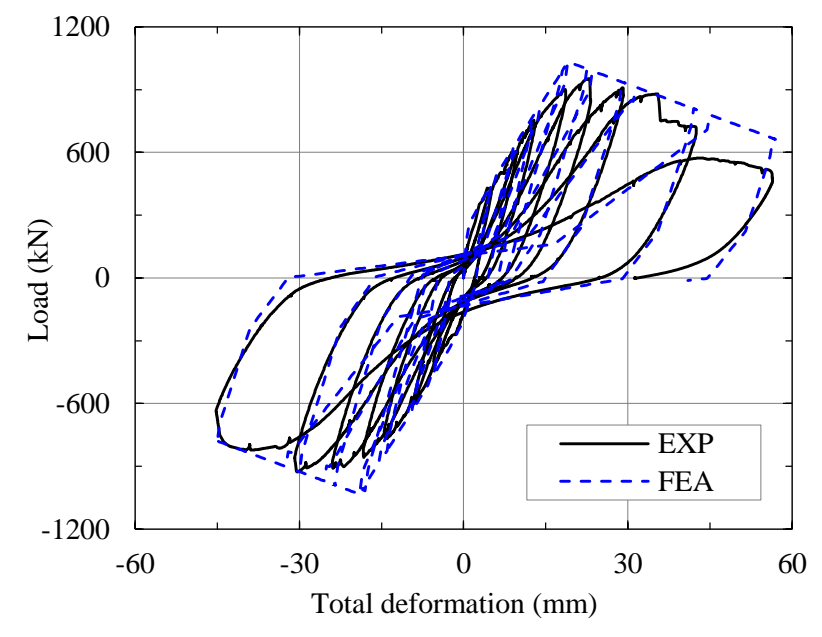

(a) total displacement 


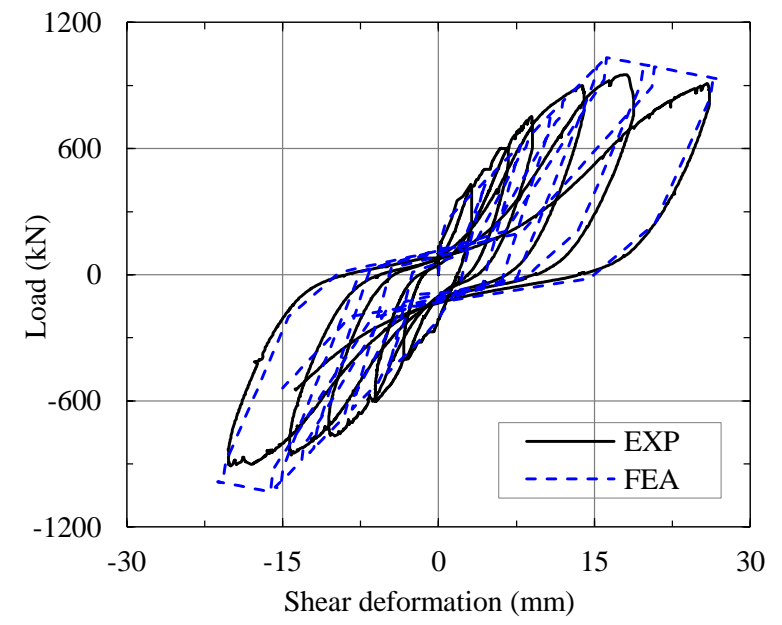

(b) shear deformation component

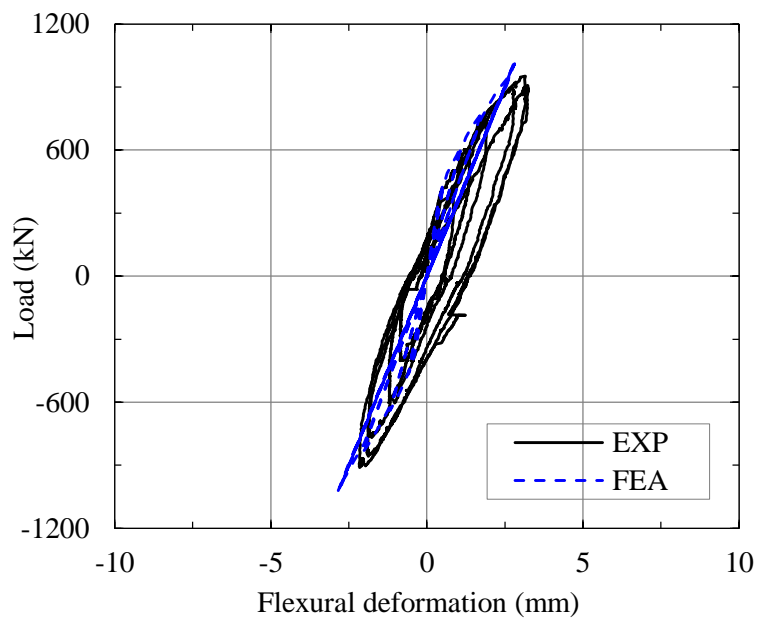

(c) flexural deformation component

Fig. 14. Comparison between experimental and FE results: load-displacement relationships

\subsection{High-efficiency modeling scheme for composite frame slabs}

323 The experimental simulations showed that the MVLEM based on the fiber beam-column program

324 could capture the in-plane behavior of a composite frame slab with a reasonable level of accuracy.

325 This section further establishes a high-efficiency modeling scheme of composite frame slabs considering both the in-plane and out-of-plane effects of the slab.

As discussed in the Introduction, effective models for composite frame slabs may be classified into two categories, namely, refined models and high-efficiency models. A typical refined model is shown in Fig. 15(a). This model simulates the slab as multilayer shell elements $[5,13,14]$. The beam elements that are connected to the shell elements use only a steel section. By specifying appropriate material constitutive relationships, the in-plane effect of the slab can be well predicted by the shell elements. The out-of-plane composite effect of the slab is simulated directly through the connection between the beam elements and the shell elements.

An illustration of high-efficiency models is shown in Fig. 15(b). Compared to the refined model, the beam elements are established using a composite section that considers the effective slab widths 

influence of the out-of-plane composite effect of the slab on the cyclic behavior of the composite beam can be simulated by this composite cross-section. The in-plane effect of the slab is simulated by using a high-efficiency modeling scheme.

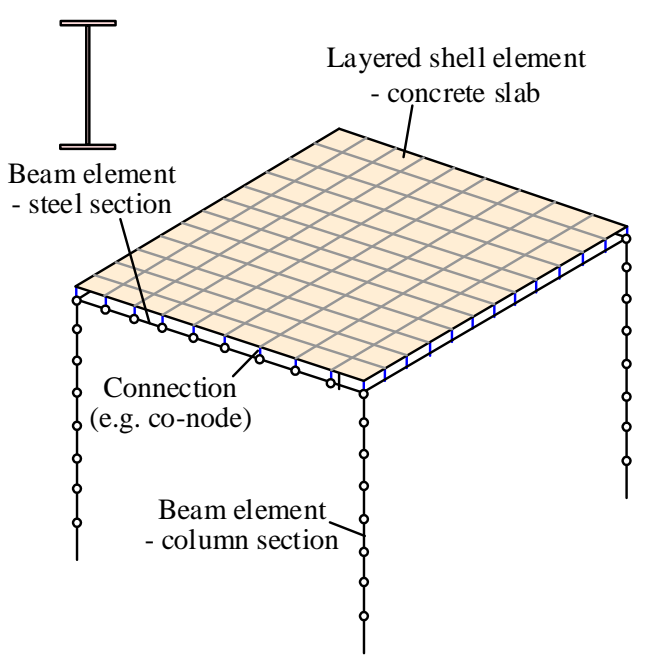

(a) refined model

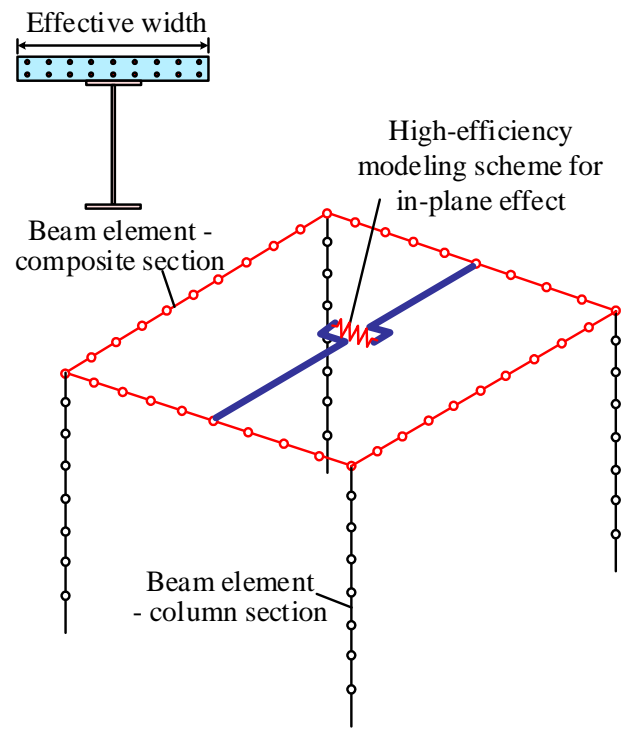

(b) high-efficiency model

Fig. 15. Modeling of composite frame considering both in-plane and out-of-plane effects of the slab of the MVLEM can then be simulated by the axial deformation of the vertical line elements. By specifying the shear element as the shear deformation-based fiber beam-column element $[35,36]$ in 

and out-of-plane effects of the composite frame slab.

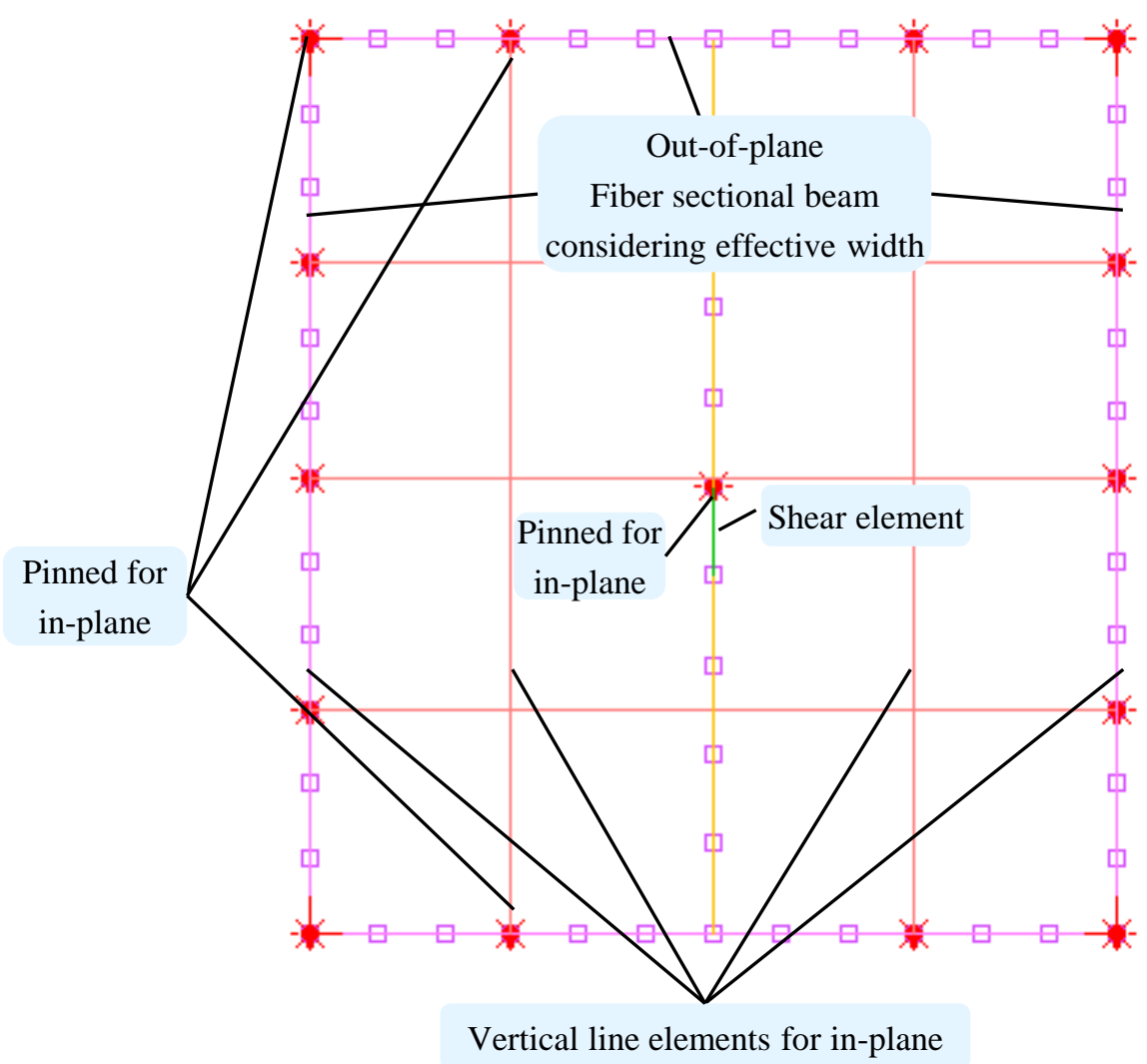

Fig. 16. Two-way MVLEM modeling scheme for both the in-plane and out-of-plane effects of the composite frame slab

\section{Concluding remarks}

This paper presents experimental and numerical investigations on the in-plane behavior of steel-

1. The composite frame slab under the in-plane loading test showed a typical shear-tension failure mode marked by the concentration of major diagonal cracks because of a relatively low reinforcement ratio. Due to this failure mode, the load-displacement relationship demonstrated evident stiffness and strength degradations and a pinching effect of the hysteretic curve. The shear 
and flexural deformation measurements of the specimen also proved the shear-dominant failure mode because the shear deformation component accounts for more than $90 \%$ in the total deformation.

2. The specimen under the in-plane loading test could be simulated by using the multiple vertical line element model (MVLEM) based on the fiber-element-based program COMPONA-MARC. The developed model was able to capture the shear-dominant failure mode, the overall loaddisplacement relationship, and the relationships associated with the shear and flexural deformation components with a reasonable level of accuracy.

3. Considering both the in-plane and out-of-plane effects of the slab, the proposed fiber-elementbased MVLEM modeling scheme for composite frames and frame slabs furnishes some to-use in the analysis and design.

\section{Acknowledgements}

378 The writers gratefully acknowledge the financial support provided by the National Natural Science 379 Foundation (Grant No. 51878378) and the National Key Research and Development Program of 380 China (Grant No. 2018YFC0705700).

\section{References}

382 1. Bursi OS, Gramola G. Behaviour of composite substructures with full and partial shear connection under quasi-static cyclic and pseudo-dynamic displacements. Materials and Structures, 2000, 33(3): 154-163. 
2. Udagawa K, Mimura H. Behavior of composite beam frame by pseudodynamic testing. ASCE Journal of Structural Engineering, 1991, 117(5): 1317-1334.

3. Nakashima M, Matsumiya T, Suita K, Zhou F. Full-scale test of composite frame under large cyclic loading. ASCE Journal of Structural Engineering, 2007, 133(2): 297-304.

4. Tagawa Y, Kato B, Aoki H. Behavior of composite beams in steel frame under hysteretic loading. ASCE Journal of Structural Engineering, 1989, 115(8): 2029-2045.

5. Nie JG, Pan WH, Tao MX, Zhu YZ. Experimental and numerical investigations of composite frames with innovative composite transfer beams. ASCE Journal of Structural Engineering, 2017, 143(7): 04017041.

6. Nie JG, Tao MX. Slab spatial composite effect in composite frame systems. I: Effective width for ultimate loading capacity. Engineering Structures, 2012, 38: 171-184.

7. Nie JG, Tao MX. Slab spatial composite effect in composite frame systems. II: Equivalent stiffness and verifications. Engineering Structures, 2012, 38: 185-199.

8. Tao MX, Nie JG. Fiber beam-column model considering slab spatial composite effect for nonlinear analysis of composite frame systems. ASCE Journal of Structural Engineering, 2014, 140(1): 04013039.

9. Spacone E, Filippou FC, Taucer FF. Fibre beam-column model for non-linear analysis of R/C

10. Spacone E, Filippou FC, Taucer FF. Fibre beam-column model for non-linear analysis of R/C 
407 11. Tao MX, Nie JG. Element mesh, section discretization and material hysteretic laws for fiber 408 beam-column elements of composite structural members. Materials and Structures, 2015, 48(8): 2521-2544.

12. Pan WH, Tao MX, Nie JG. Fiber beam-column element model considering reinforcement anchorage slip in the footing. Bulletin of Earthquake Engineering, 2017, 15(3): 991-1018.

412 13. Tao MX, Nie JG. Multiscale modeling for deformation mechanism analysis of composite joint $413 \quad$ substructures. Engineering Structures, 2016, 118: 55-73.

414 14. Lu XZ, Xie LL, Guan H, Huang YL, Lu X. A shear wall element for nonlinear seismic analysis 415 of super-tall buildings using OpenSees. Finite Elements in Analysis and Design, 2015, 98: 14-25. 416 15. Blume JA, Sharpe RL, Elsesser E. A structural dynamic investigation of fifteen school buildings 417 subjected to simulated earthquake motion. Department of Public Works, Division of Agriculture, 418 Sacramento, CA, 1961.

419 16. Jain SK. Seismic response of buildings with flexible floors. ASCE Journal of Engineering Mechanics, 1984, 110(1): 125-129.

421 17. Moon SK, Lee DG. Effects of inplane floor slab flexibility on the seismic behaviour of building structures. Engineering Structures, 1994, 16(2): 129-144.

18. Fleischman RB, Farrow KT. Dynamic behavior of perimeter lateral-system structures with flexible diaphragms. Earthquake Engineering and Structural Dynamics, 2001, 30(5): 745-763. structures. Engineering Structures, 2006, 29(7): 1375-1397. 
20. Lee HJ, Kuchma D, Aschheim MA. Strength-based design of flexible diaphragms in low-rise structures subjected to earthquake loading. Engineering Structures, 2006, 29(7): 1277-1295.

21. Nakashima M, Huang T, Lu LW. Seismic resistance characteristics of reinforced concrete beamsupported floor slabs in building structures (Ph.D. dissertation). Report No. 422.9, Lehigh University, Bethlehem, PA, 1981.

22. Nakashima M, Huang T, Lu LW. Experimental study of beam-supported slabs under in-plane loading. ACI Journal Proceedings, 1982, 79(1): 59-65.

23. Chen SJ. Reinforced concrete floor slabs under in-plane monotonic and cyclic loading (Ph.D. dissertation). Report No. 481.6, Lehigh University, Bethlehem, PA, 1986.

24. Wu ZS, Huang T. An elastic analysis of a cantilever slab panel subjected to an in-plane end shear. Report No. 481.1, Lehigh University, Bethlehem, PA, 1983.

25. Panahshahi N, Reinhorn AM, Kunnath SK, Lu LW, Huang T, Yu K. Seismic response of a 1:6 reinforced concrete scale-model structure with flexible floor diaphragms. ACI Structural Journal, 1991, 88(3): 315-324.

26. Sarkissian L, Jahromi KK, Zahrai SM. Study of the diaphragm behavior of composite floor systems under lateral cyclic in-plane load with the gravity load. 6th Asia-Pacific Conference on Shock and Impact Loads on Structures, Perth, Australia, 2005.

27. Ju SH, Lin MC. Comparison of building analyses assuming rigid or flexible floors. ASCE Journal of Structural Engineering, 1999, 125(1): 25-31.

28. Saffarini HS, Qudaimat MM. In-plane floor deformations in RC structures. ASCE Journal of Structural Engineering, 1992, 118(11): 3089-3102. 
29. Faggella M, Spacone E, Conte JP, Restrepo J. Nonlinear seismic response analyses of existing $\mathrm{R} / \mathrm{C}$ building and evaluation of system components contribution. First European Conference on Earthquake Engineering and Seismology, Geneva, Switzerland, 2006.

30. Shepherd R, Donald RAH. The influence of in-plane floor flexibility on the normal mode properties of buildings. Journal of Sound and Vibration, 1967, 5(1): 29-36.

31. Tena-Colunga A, Abrams DP. Seismic behavior of structures with flexible diaphragms. ASCE Journal of Structural Engineering, 1996, 122(4): 439-445.

32. Park YJ, Reinhorn AM, Kunnath SK. IDARC: Inelastic damage analysis of reinforced concrete frame-shear-wall structures. Report No. NCCER-87-0008, National Center for Earthquake Engineering Research, State University of New York at Buffalo, Buffalo, NY, 1987.

33. Kunnath SK, Panahshahi N, Reinhorn AM. Seismic response of RC buildings with inelastic floor diaphragms. ASCE Journal of Structural Engineering, 1991, 117(4): 1218-1237.

34. Pinho R, Bhatt C, Antoniou S, Bento R. Modelling of the horizontal slab of a 3D irregular building for nonlinear static assessment. 14th World Conference on Earthquake Engineering, Beijing, China, 2008.

35. Ding R, Tao MX, Nie JG, Mo YL. Shear deformation and sliding-based fiber beam-column model for seismic analysis of reinforced concrete coupling beams. ASCE Journal of Structural Engineering, 2016, 142(7): 04016032.

36. Ding R, Tao MX, Nie X, Mo YL. Fiber beam-column model for diagonally reinforced concrete coupling beams incorporating shear and reinforcement slip effects. Engineering Structures, 2017, 153: 191-204 
37. Vecchio FJ, Collins MP. The modified compression-field theory for reinforced concrete elements subjected to shear. ACI Structural Journal, 1986, 83(2): 219-231.

38. Hsu TTC, Zhu RRH. Softened membrane model for reinforced concrete elements in shear. ACI Structural Journal, 2002, 99(4): 460-469.

39. Mansour M, Hsu TTC. Behavior of reinforced concrete elements under cyclic shear. II: Theoretical model. ASCE Journal of Structural Engineering, 2005, 131(1): 54-65.

40. Maekawa K, Okamura H, Pimanmas A. Non-linear mechanics of reinforced concrete. CRC Press, 2003.

41. Moharrami M., Koutromanos I. Triaxial constitutive model for concrete under cyclic loading.

42. Wang JJ, Liu C, Fan JS, Hajjar JF, Nie X. Triaxial concrete constitutive model for simulation of ASCE Journal of Structural Engineering, 2016, 142(7): 04016039.

43. Vulcano A., Bertero VV, Colotti V. Analytical modeling of RC structural walls. 9th World Conference on Earthquake Engineering, Tokyo, Japan, 1988.

44. Orakcal K, Wallace JW, Conte JP. Flexural modeling of reinforced concrete walls-model attributes. ACI Structural Journal, 2004, 101(5): 688-698.

45. Kolozvari K, Orakcal K, Wallace J. Shear-flexure interaction modeling for reinforced concrete structural walls and columns under reversed cyclic loading. Report No. 2015/12, Pacific Earthquake Engineering Research Center, University of California, Berkeley, CA, 2015. 